УДК 553.98

\title{
ТЕПЛОВОЙ ПОТОК И НЕФТЕГАЗОНОСНОСТЬ СЕВЕРО-ВОСТОЧНОЙ ЧАСТИ ТОМСКОЙ ОБЛАСТИ
}

\author{
Лобова Галина Анатольевна', \\ lobovaga@tpu.ru
}

\author{
Меренкова Анна Сергеевна ${ }^{1}$, \\ a.merenckowa@yandex.ru \\ Исаев Валерий Иванович1, \\ isaevvi@tpu.ru \\ Кузьменков Станислав Григорьевич2, \\ ksg.1948@yandex.ru \\ 1 Национальный исследовательский Томский политехнический университет, \\ Россия, 634050, г. Томск, пр. Ленина, 30. \\ 2 Югорский государственный университет, \\ Россия, 628012, г. Ханты-Мансийск, ул. Чехова, 16.
}

\begin{abstract}
Актуальность исследования северо-восточной части Томской области определяется необходимостью поисков новых источников пополнения ресурсной базы, определенных стратегией развития нефтяной отрасли Российской Федерации до 2035 ح.

Целью данного исследования является определение плотности теплового потока и выполнение корреляции аномальных зон полученного параметра с установленной нефтегазоносностью, определение перспективности северо-восточных земель Томской области для нижнеюрских и доюрских отложений.

Объектом исследования являются северо-восточные земли Томской области, относящиеся к территории широкого распространения геттанг-нижнетоарских потенциальных нефтематеринских тогурских отложений и имеющие определенное сходство геологического строения с нефотепромысловыми районами. Для определения плотности теплового потока использованы температуры, измеренные в 38 поисково-разведочных и параметрических представительных скважинах.

Методы исследования включают сбор и анализ геолого-геофизических данных по глубоким скважинам, пробуренным на территории исследования, и палеотемпературное моделирование $1 D$, совмещенное с палеотектоническими реконструкциями $c$ применением отечественного программного продукта.

Результаты. По расчетным значениям теплового потока в скважинах методом интерполяции построена карта с сечением изолиний 2,5 мBm/ $\mathrm{M}^{2}$. Анализ выполненных построений показывает, что тепловое поле на кровле фрундамента в северовосточной части Томской области неоднородно. Его значения изменяются от 33 до $69 \mathrm{mBm} / \mathrm{M}^{2}$. Зона повышенных значений плотности теплового потока простирается с северо-запада на юго-восток, пересекая тектонические структуры. На северо-восточных и восточных участках наблюдается снижение напряженности геотермического поля. Повышенные значения теплового потока в основном коррелируют с установленной нефтегазоносностью на территории исследования. В пределах южной части Карамкинского мезопрогиба предполагается высокая перспективность в нижнеюрском и доюрском комплексах. Высокие перспективы нефртегазоносности можно отметить в районе параметрической скважины Южно-Пьжинская 1 и земель, расположенных в Восточно-Пайдугинской мегавпадине, где увеличены мощности нижнеюрских отложений и величина теплового потока.

Выводы. Получены новые данные о плотности теплового потока на северо-востоке Томской области. Территория исследования перспективна для проведения дальнейших поисково-разведочных работ с иелью открытия залежей в нижнеюрских и доюрских объектах.
\end{abstract}

\section{Ключевые слова:}

Нефртематеринские тогурские отложения, палеотемпературное моделирование, плотность теплового потока, нефртегазоносность, нижнеюрские и доюрские отложения, северо-восток Томской области.

\section{Введение}

Потребность в новых источниках пополнения ресурсной базы в Томской области является весьма назревшей задачей. По принятой стратегии развития Российской Федерации до 2035 г. задача нефтяной отрасли в Западной Сибири - прирастить запасы УВ за счет изучения и освоения малоизученных территорий [1]. Перспективы нефтегазоносности земель напрямую связаны с наличием как резервуаров, так и нефтематеринских отложений. В северо-восточной части Томской области интерес представляют нижнеюрский и доюрский нефтегазоносные комплексы, для которых потенциально нефтематеринскими являются тогурские отложения, имеющие широкое распространение на этих землях.

В пределах Томской области ранее выполнены исследовательские работы в Нюрольской, Усть-Тымской мегавпадинах, Колтогорском мезопрогибе, Бакчарской мезовпадине (рис. 1), включающие бассейновое моделирование и ранжирование территории по степени перспективности для проведения дальнейших поисковых работ на горизонты нижней юры и палеозоя. Наиболее крупный Верхнекетский геттанг-раннетоарский седиментационный бассейн, расположенный в восточной ча- 
сти Томской области и имеющий сходное геологическое строение [2], также представляет определенный интерес в нефтегазоносном отношении и является объектом исследования в данной работе.

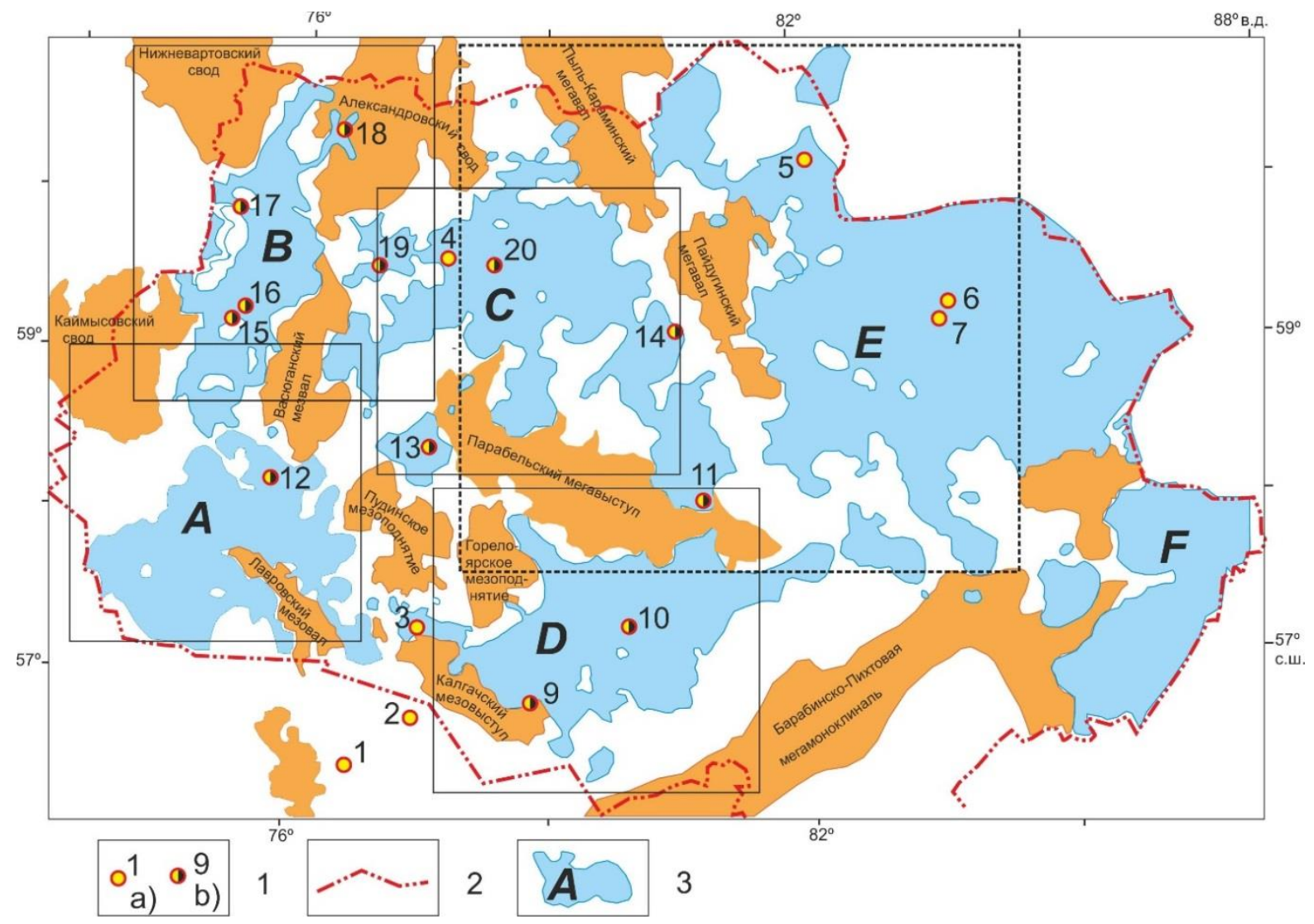

Pис. 1. Схема областей накопления нижнеюрских нефтематеринских отложений (по [2, 3] с доработкой). 1 скважина, вскрывшая тогурскую свиту: получен приток (а); изучен керн (б); 2 - контур Томской области; 3 - геттанг-нижнетоарские седиментационные бассейны: $A$ - Нюрольский, B - Колтогорский, $C$ - УстьТымский, D - Бакчарский, E- - ерхнекетский, F- Тегульдетский. Сплошной черной линией обозначень участки ранее выполненных исследований на основе палеотемпературного моделирования [3-5]. Положение территории исследования показано пунктирной линией

Fig. 1. Scheme of accumulation areas of Lower Jurassic oil source suites (according to [2, 3] with revision): 1 - the well penetrated the Togur suite: inflow (a) received; core studied (b); 2 -the Tomsk region outline; 3 -Hettangian-Lower Toarcian sedimentation basins: A - Nurolka; B - Koltogor; C - Ust-Tym; D - Bakchar; E - Verkchneket; $F$ - Teguldet. The solid black line denotes areas of earlier studies based on paleotemperature modeling [3-5]. The location of the study area is shown with a dashed line

Известно, что геотемпература является важным прогностическим критерием [6-8], поэтому исследования направлены на определение величины теплового потока из кровли фундамента, построение карты и прослеживание связи между установленной нефтегазоносностью и аномальными зонами полученного параметра.

\section{Краткая характеристика нефтегазоносности территории}

Территория исследования охватывает центральную и западную части Верхнекетского, западную часть Усть-Тымского и северный участок Бакчарского геттанг-нижнетоарских седиментационных бассейнов. Исследуемый район частично перекрывает ранее изученные земли на стыках территорий.

В тектоническом отношении исследование проводится в Восточно-Пайдугинской, Усть-Тымской мегавпадинах, Бакчарской мезовпадине и структурах их обрамления.

На северо-западе территории исследования, где нефтематеринские волжские отложения (возрастной аналог баженовской свиты) формируются в прибрежных фациальных условиях (переходная зона), содержание $\mathrm{C}_{\text {орг }}$ достигает $7 \%$, мощность толщи $20 \mathrm{~m}$, градация катагенеза $\mathrm{M}_{1}{ }_{1}^{1}$, открыто 5 месторождений с залежами нефти в верхнеюрском и меловом комплексах (рис. 2). В пределах северного склона Парабельского мегавыступа открыты газоконденсатные верхнеюрские залежи на месторождениях Сильгинской группы. Далее на восток промышленная нефтегазоносность верхнеюрского и мелового НГК не установлена, вероятнее всего, это связано со снижением генерационного потенциала волжской нефтематеринской свиты.

Таким образом, основной интерес представляют нижнеюрский и доюрские комплексы, для которых потенциально нефтематеринскими являются тогурские породы, которые имеют широкое распространение на территории исследования и, по данным исследователей $[2,9]$, обладают достаточным нефтематеринским потенциалом. 
Отмечается неоднородность РОВ в тогурских отложениях, здесь присутствуют как гумусовая, так и сапропелевая составляющие [10]. В приведенных результатах изучения с использованием современных методов аналитической органической геохимии нижнеюрских пород в скважинах, расположенных в восточной части территории исследования, показано, что значение $\mathrm{C}_{\text {орг достигает }}$ в урманской свите (скв. Восток-3) до 2 \%, а водородный индекс достигает 38 мг УВ/г $\mathrm{C}_{\text {орг }}$, что указывает на принадлежность основной части РОВ к террагенному генезису [11]. Стадия катагенеза органического вещества достигает градации $\mathrm{MK}_{1}{ }^{1-}$ $\mathrm{MK}_{1}^{2}$, что подтверждает катагенетическую зрелось битумоидов.
Нижнеюрские толщи в наиболее прогнутых участках характеризуются присутствием в разрезе урманской, тогурской и пешковской свит с пластами-коллекторами $\left(Ю_{17}, Ю_{16}\right.$ и $\left.Ю_{15}\right)$, покрышками для которых служат глинистые толщи китербютского и лайдинского горизонтов [12]. Вскрытые пласты имеют прямые признаки нефтенасыщения (рис. 2). Из нижнеюрских толщ получены: приток воды с пленкой нефти из пласта Ю 14 пешковской свиты в скважине Южно-Пыжинская 1 и разгазированная нефть в интервалах залегания пластов Ю $_{16-17}$ урманской свиты в Толпаровской 1.

Таким образом, полученные результаты геологоразведочных работ на территории исследования подтверждают ее перспективность и позволяют выполнить «нефтегеологическое моделирование» [13-15].

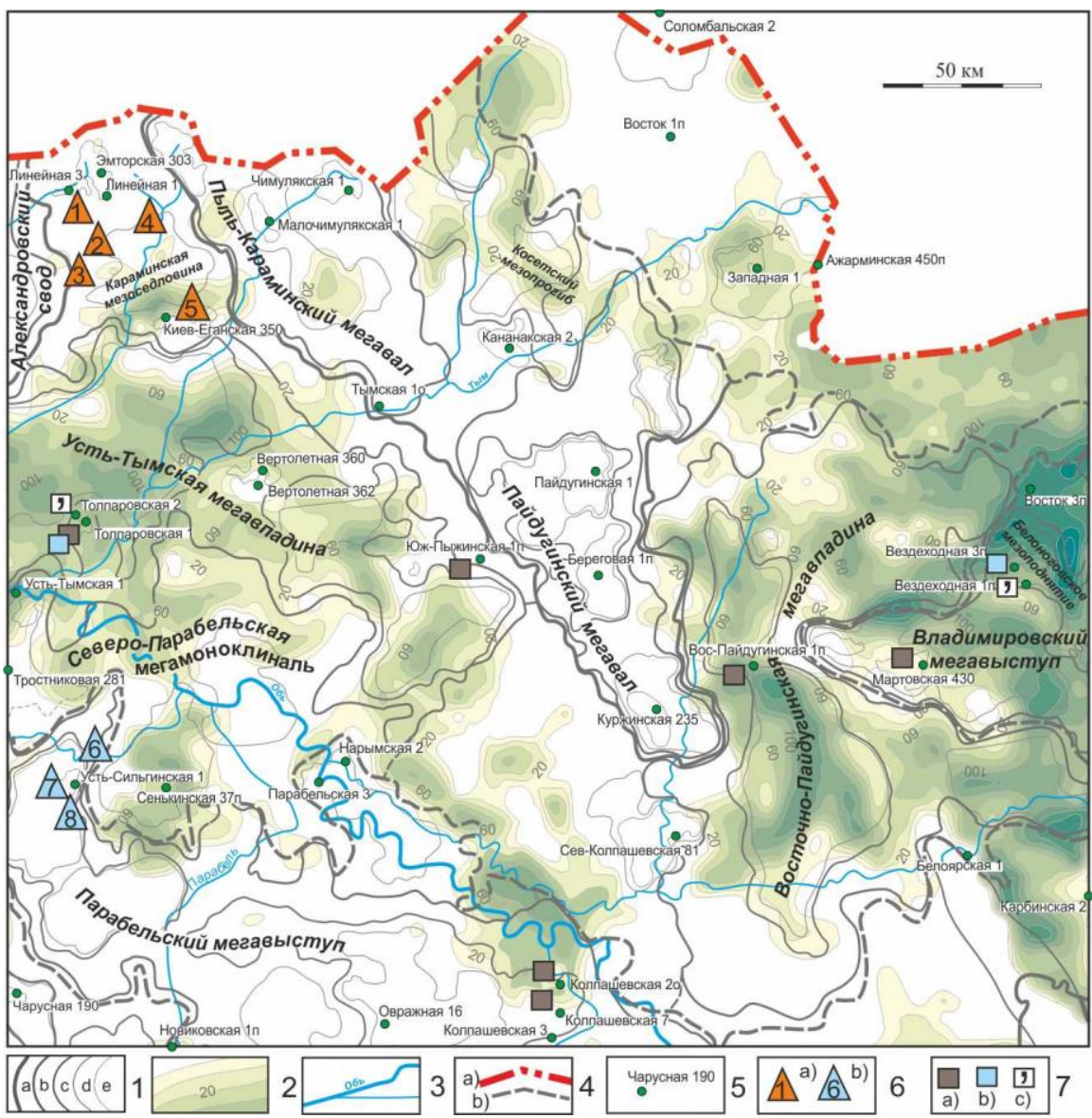

Pис. 2. Обзорная схема нефтегазоносности северо-восточной части Томской области на тектонической основе юрского структурного яруса с границей распространения тогурских нефтематеринских отложений (с использование [2]): 1 - контур тектонической структур: надпорядковая (a), I-IV порядка (b-e); 2 - изопахиты тогурских отложений с сечением 20 м; 3 - речная сеть; 4 - граница: Томской области (a), условная для «переходной зоны» от Западно-Сибирской плиты к Енисейскому кряжу (б); 5 -моделируемая скважина; 6 -месторождения углеводородов: нефти (а): 1 - Линейное, 2 - Кондрашовское, 3 - Тунгольское, 4 - КиевЕганское, 5 - Арбузовское; газоконденсатное (b): 6 - Северо-Сильгинское, 7 - Усть-Сильгинское, 8 - Среднесильгинское; 7 - прямые признаки нефтегазоносности в нижнеюрском и доюрском НГК: непромышленный приток нефти (a), газа (b); запах нефти в керне (c)

Fig. 2. Overview scheme of oil and gas presence of the Tomsk region north-eastern part on the Jurassic structural stage tectonic foundation with the boundary of Togur oil source deposits distribution (using [2]): 1 - boundaries of tectonic structures: supra-order (a), I-IV order (b-e); 2 - isopachous lines of the Togur deposits with a section of $20 \mathrm{~m}$; 3 - river system; 4 - boundary of Tomsk region (a), conditional border of the «transition zone» from the West Siberian plate to the Yenisei ridge (b); 5 - the simulated well; 6 - hydrocarbon fields: of oil (a): 1 - Lineynoe, 2 - Kondrashovskoe, 3 - Tungolskoe, 4 - Kiev-Eganskoe, 5 -Arbuzovskoe; of gas and condensate (c): 6 - Severo-Silginskoe, 7 -Ust-Silginskoe, 8 -Srednesilginskoe; 7 - direct signs of oil and gas presence obtained in the Lower Jurassic and pre-Jurassic oil and gas complexes: noncommercial flow of oil (a), gas (b); the smell of oil in the core (c) 
На данном этапе исследований ставится задача определить и закартировать распределение теплового потока из кровли фундамента, и установить степень корреляции его значений с доказанной нефтегазоносностью.

\section{Методика расчета теплового потока}

Для выполнения исследований используется программное обеспечение «TeploDialog»[16], позволяющее проводить нефтегеологическое моделирование $1 \mathrm{D}$ с учетом местного изменения поверхностной температуры в геологическом прошлом. Это программное обеспечение по своим результатам не уступает известным программам бассейнового моделирования, таким как BasinMod, Temis Flow, PetroMod, TECMOD2D [17-20]. Преимущество применяемой компьютерной технологии состоит в том, что определение теплового потока не требует сведений об условиях его внутреннего источника, подтверждение которых также нуждается в убедительных фактах о их существовании.

Методика расчета теплового потока из кровли фундамента заключается в решении обратной линейной задачи геотермии [21]. Для решения используется статистическая модель распределения коэффициента теплопроводности в каждой свите осадочного разреза с верхним граничным условием, соответствующим изменению климата в прошлые геологические эпохи на поверхности Земли в изучаемом районе [22]. При этом решение задачи является однозначным, так как принимается допущение квазипостоянства теплового потока, который по оценкам [23], начиная с юрского периода, изменялся в пределах $5 \%$.

При отсутствии на территории исследований экспериментальных определений теплопроводности свит осадочного чехла используются петрофизические зависимости теплопроводности осадков от их литологии и плотности [6]. Коэффициенты температуропроводности, плотности тепловыделения радиоактивных источников определяются литологией стратиграфических комплексов.

Необходимо отметить, что вклад радиоактивных источников тепла осадочного разреза может быть ощутимым, в зависимости от мощности осадочного чехла на конкретный момент геологического времени. Поэтому этот фактор алгоритмически учитывается решением прямых задач геотермии при расчете геотемператур осадочных комплексов.

Для палеотемпературного моделирования используются литолого-стратиграфические разбивки глубоких скважин, температуры, полученные как при испытании интервалов с существенными притоками флюида, так и определенные по геотермии в скважинах, выдержанных в состоянии покоя необходимое время после завершения работ (материалы предоставлены томским территориальным фондом геологической информации).

В качестве исходных используются также палеотемпературы, пересчитанные из отражательной способности витринита (материалы предоставлены Институтом нефтегазовой геологии и геофизики СО РАН).
Для моделирования проанализированы 63 скважины, из них отобраны 38 наиболее представительных и соответствующих требованиям измерения исходных температур.

Достоверность результатов моделирования обеспечивается сходимостью расчетных и измеренных температур, равной среднеквадратичной погрешности измерений. В наших расчетах сходимость («невязка») составила порядка $\pm 2{ }^{\circ} \mathrm{C}$ (таблица), что соответствует погрешности определения измеренных температур [7]

В процессе выполнения расчетов для четырех скважин: Кананакская 2, Ажарминская 450, Восток 1 и Вездеходная 3, было установлено, что совместное применение в качестве наблюденных палеотемператур, определённых из ОСВ, и геотемператур, определенных в современном разрезе, приводит к расхождению наблюденных и расчетных температур выше допустимых значений. Расчеты выполнены в двух вариантах, в каждом из которых учитывался только один тип наблюденных температур. При построении карты использовалось среднее значение между двумя итерациями. Однако этот вопрос требует отдельной проработки, так как, вероятно, имеет место проявление процессов эрозии, что рекомендуется учитывать при построении модели [24-28].

По полученным значениям теплового потока в скважинах методом интерполяции построена карта с сечением изолиний 2,5 мВт/м² (рис. 3 ).

\section{Анализ карты теплового потока}

Анализ выполненных построений показывает, что тепловое поле на кровле фундамента в северовосточной части Томской области неоднородно. Его значения изменяются от 33 до 69 мВт/м² (рис. 3).

Отмечается зона повышенных значений плотности теплового потока, простирающаяся с северозапада на юго-восток и пересекающая при этом как положительные тектонические структуры, так и отрицательные. Высокие значения теплового потока отмечались ранее на Александровском вале, расположенном в северной части территории исследования. Такой же тепловой режим сохраняется и восточнее, в пределах Караминской мезоседловины, достигая максимума в скважине Куль-Еганская 350 $\left(63 \mathrm{mBT} / \mathrm{m}^{2}\right)$. Юго-восточная аномалия закартирована на Колпашевской структуре, плотность теплового потока в 69 мВт/м² зафиксирована в скважине 2 .

Можно усомниться в значении $60 \mathrm{MBT} / \mathrm{M}^{2}$ в Белоярской скважине в связи с ее близостью к Карбинской 2, где получено значение в $42 \mathrm{mBT} / \mathrm{m}^{2}$. Скважины находятся в тектоническом плане в «переходной» зоне от Западно-Сибирской плиты к байкалидам Енисейского кряжа, для которых характерно понижение теплового потока.

В северо-восточном и восточном направлении наблюдается снижение напряженности геотермического поля. Локальная аномалия с понижением теплового потока до $33 \mathrm{mBT} / \mathrm{m}^{2}$ отмечается в «переходной» зоне от Западно-Сибирской плиты к Енисейскому кряжу.

В восточном направлении идет постепенно снижение плотности теплового потока, что соответствует данным, полученным ранее $[4,6]$. 
Таблица. Сопоставления измеренных и расчетных температур, рассчитанные значения плотности теплового потока в моделях скважин

Table. $\quad$ Comparison of the measured and calculated temperatures, calculated values of heat flux density in the study area

\begin{tabular}{|c|c|c|c|c|c|c|c|}
\hline \multirow[b]{2}{*}{$\begin{array}{l}\text { Скважина, ее условный индекс (рис. 3) } \\
\text { Well, its conditional field index (Fig. 3) }\end{array}$} & \multirow[b]{2}{*}{ 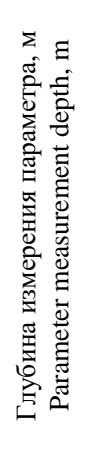 } & \multicolumn{5}{|c|}{ Температура/Temperature, ${ }^{\circ} \mathrm{C}$} & \multirow[b]{2}{*}{ 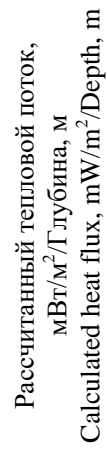 } \\
\hline & & 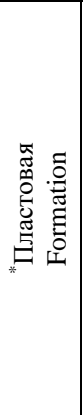 & 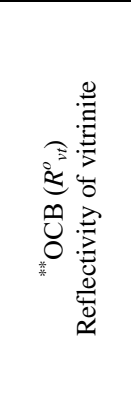 & 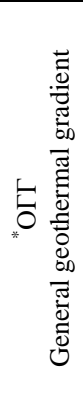 & 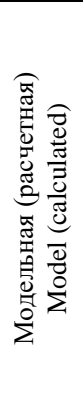 & 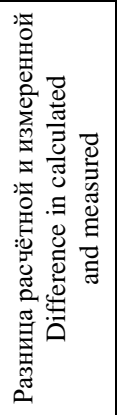 & \\
\hline \multirow{9}{*}{$\begin{array}{c}\text { Береговая параметрическая 1, Б1п } \\
\text { Beregovaya parametric } 1\end{array}$} & 2415 & 83 & - & - & 80 & -3 & \multirow{10}{*}{$49 / 2576$} \\
\hline & 2330 & 78 & - & - & 77 & -1 & \\
\hline & 2500 & $\begin{array}{lll}- & & \\
\end{array}$ & - & 81 & 82 & 1 & \\
\hline & 2390 & - & $99(0,64)$ & - & 96 & -3 & \\
\hline & 2405 & - & $99(0,64)$ & - & 96 & -3 & \\
\hline & 2410 & - & $99(0,64)$ & - & 97 & -2 & \\
\hline & 2449 & - & $99(0,64)$ & - & 98 & -1 & \\
\hline & 2560 & - & $103(0,68)$ & - & 101 & 2 & \\
\hline & 2573 & $\begin{array}{ll}- \\
-\end{array}$ & $100(0,65)$ & - & 102 & 2 & \\
\hline \multicolumn{6}{|c|}{$\begin{array}{l}\text { Среднеквадратическое отклонение, }{ }^{\circ} \mathrm{C} \\
\text { Mean squared error («true error»), }{ }^{\circ} \mathrm{C}\end{array}$} & \pm 2 & \\
\hline \multirow{7}{*}{$\begin{array}{l}\text { Вертолетная } 360, \text { В360 } \\
\text { Vertoletnaya } 360\end{array}$} & 2605 & 85 & - & - & 86 & 1 & \multirow{8}{*}{$48 / 3121$} \\
\hline & 2580 & 84 & - & - & 85 & 1 & \\
\hline & 2680 & 90 & - & - & 88 & -2 & \\
\hline & 2535 & 82 & - & - & 84 & 2 & \\
\hline & 2465 & 80 & $\begin{array}{llll}- & & & \end{array}$ & $\begin{array}{llll}- & & & \\
\end{array}$ & 82 & 2 & \\
\hline & 2622 & - & $105(0,69)$ & - & 102 & -3 & \\
\hline & 2656 & - & $105(0,69)$ & - & 103 & -2 & \\
\hline \multicolumn{6}{|c|}{$\begin{array}{c}\text { Среднеквадратическое отклонение, }{ }^{\circ} \mathrm{C} \\
\text { Mean squared error («true error»), }{ }^{\circ} \mathrm{C}\end{array}$} & \pm 2 & \\
\hline \multirow{4}{*}{$\begin{array}{l}\text { Усть-Сильгинская (УС1) } \\
\text { Ust-Silginskaya } 1\end{array}$} & 2040 & - & $\begin{array}{lll}- & \\
\end{array}$ & 58 & 59 & 1 & \multirow{5}{*}{$42 / 2531$} \\
\hline & 2270 & - & - & 64 & 65 & 1 & \\
\hline & 2440 & - & - & 70 & 69 & -1 & \\
\hline & 2500 & $\begin{array}{llll}- & \\
\end{array}$ & $\begin{array}{llll}- & & & \end{array}$ & 72 & 71 & -1 & \\
\hline \multicolumn{6}{|c|}{$\begin{array}{l}\text { Среднеквадратическое отклонение, }{ }^{\circ} \mathrm{C} \\
\text { Mean squared error («true error»), }{ }^{\circ} \mathrm{C}\end{array}$} & \pm 1 & \\
\hline \multirow{6}{*}{$\begin{array}{c}\text { Южно-Пыжинская } 1 \text { параметрическая (ЮПы1п) } \\
\text { Yuzhno-Pyzhinskaya parametric } 1\end{array}$} & 2598 & - & $116(0,76)$ & - & 114 & -2 & \multirow{7}{*}{$56 / 3127$} \\
\hline & 2618 & - & $117(0,77)$ & - & 115 & -2 & \\
\hline & 2643 & - & $116(0,76)$ & - & 116 & 0 & \\
\hline & 2705 & $\begin{array}{llll}- & & & \\
\end{array}$ & $119(0,79)$ & $\begin{array}{llll}- & & & \\
\end{array}$ & 122 & 3 & \\
\hline & 2770 & $\begin{array}{llll}- & & & \\
\end{array}$ & $119(0,79)$ & $\begin{array}{llll}- & & & \\
\end{array}$ & 118 & -1 & \\
\hline & 2802 & - & $119(0,79)$ & - & 120 & 1 & \\
\hline \multicolumn{6}{|c|}{$\begin{array}{l}\text { Среднеквадратическое отклонение, }{ }^{\circ} \mathrm{C} \\
\text { Mean squared error («true error»), }{ }^{\circ} \mathrm{C} \\
\end{array}$} & \pm 2 & \\
\hline \multirow{4}{*}{$\begin{array}{l}\text { Нарымская 2, (Нар2) } \\
\text { Narymskaya } 2\end{array}$} & 2370 & - & - & 75 & 76 & 1 & \multirow{5}{*}{$47 / 2717$} \\
\hline & 2520 & - & - & 82 & 83 & 1 & \\
\hline & 2800 & - & - & 89 & 88 & -1 & \\
\hline & 2850 & - & - & 91 & 90 & -1 & \\
\hline \multicolumn{6}{|c|}{$\begin{array}{c}\text { Среднеквадратическое отклонение, }{ }^{\circ} \mathrm{C} \\
\text { Mean squared error («true error»), }{ }^{\circ} \mathrm{C}\end{array}$} & \pm 1 & \\
\hline Тымская 1 опорная (Т1o) & 2290 & - & - & 67 & 68 & 1 & \multirow{3}{*}{$43 / 2921$} \\
\hline Tymskaya key 1 & 2480 & - & - & 75 & 74 & -1 & \\
\hline \multicolumn{6}{|c|}{$\begin{array}{l}\text { Среднеквадратическое отклонение, }{ }^{\circ} \mathrm{C} \\
\text { Mean squared error («true error»), }{ }^{\circ} \mathrm{C}\end{array}$} & \pm 1 & \\
\hline
\end{tabular}

* Пластовые температуры и температуры метода ОГГ изучены и сведены из первичных «дел скважин (материалы Томского филиала ФБУ «Территориальный фонд геологической информаиии по СФО»);

** - OCB $\left(R_{v t}^{o}\right)$ определен в Лаборатории геохимии нефти и газа Института нефтегазовой геологии и геофизики СО PАН (г. Новосибирск).

* Formation temperature and general geothermal gradient are studied and linked from the «well file» (materials of Tomsk branch of «Territorial fund of geological information in SFD»);

${ }^{* *}-O C B\left(R^{o}{ }_{v t}\right)-V R$ is determined in the Laboratory of oil and gas geochemistry at the Institute of oil-and-gas geology and geophysics SB RAS (Novosibirsk). 


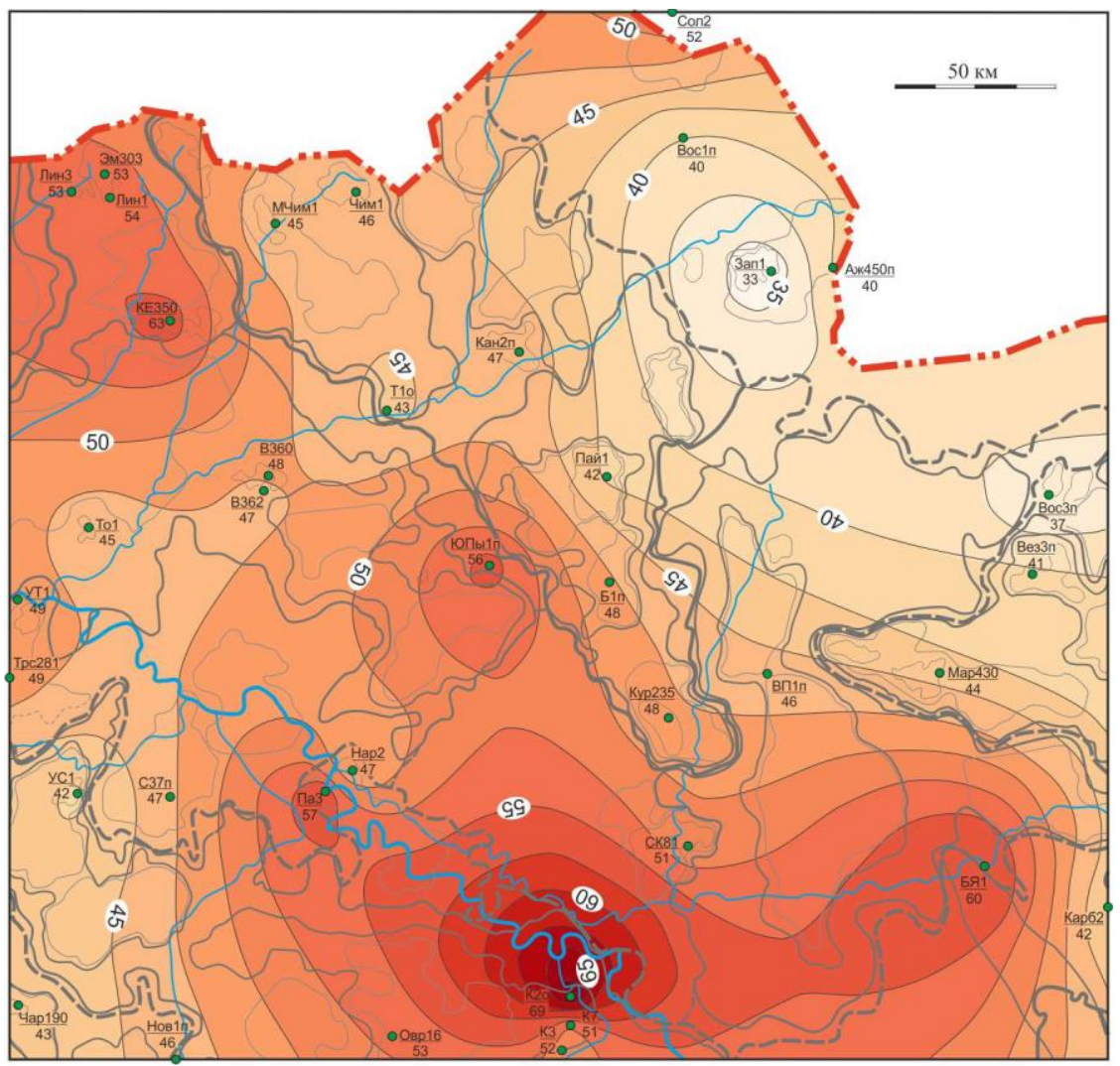

Pис. 3. Схематическая карта расчетного теплового потока северо-восточной части Томской области. Для каждой скважины указаны ее условный индекс и значение плотности теплового потока, $\mathrm{MBm} / \mathrm{m}^{2}$

Fig. 3. Map of the calculated heat flow in the north-eastern part of the Tomsk region. Conventional index and heat flow density value are given for each well, $\mathrm{mW} / \mathrm{m}^{2}$

\section{Распределение плотности теплового потока и нефтегазоносность территории}

Повышенные значения теплового потока в основном коррелируют с установленной нефтегазоносностью на территории исследования.

Катагенетическая зрелость баженовских отложений, обеспеченная повышенным тепловым потоком, привела к образованию в пределах Караминского мезопрогиба нескольких месторождений с залежами в верхнеюрском и меловом НГК (рис. 2). Поскольку тогурские отложения закартированы лишь в южной части структуры, то в контуре распространения тогура можно предположить высокую перспективность в нижнеюрском и доюрском комплексах на КиевЕганской структуре. Палеозойская толща представлена здесь глинисто-карбонатными породами инской серии $\left(\mathrm{D}_{3}-\mathrm{C}_{1}\right)$, способными к образованию зон коллекторов [29].

Высокие перспективы нефтегазоносности можно отметить в районе скважины Южно-Пыжинская 1, где получены прямые признаки нефтегазоносности и в нижнеюрском, и в доюрском НГК. Интерес представляют земли, расположенные южнее этой скважины, где увеличены мощности нижнеюрских отложений и величина теплового потока.

Повышенный тепловой поток и наличие тогура на Колпашевской структуре обусловили генерацию нефти, что доказывается притоками воды с пленкой нефти из отложений коры выветривания. Г.Д. Исаевым в 2010 г. здесь установлены зоны с высокими коллекторскими свойствами в коре выветривания. Однако, несмотря на то, что первая палеозойская нефть была получена именно здесь еще в 40-е гг. прошлого столетия, промышленных залежей до настоящего времени здесь так и не открыто. Вероятно, это обусловлено сильной преобразованностью пород палеозоя в зоне Томь-Колыванской складчатой области субмеридионального простирания.

К некоторому диссонансу можно отнести полученные прямые признаки нефтегазонасыщения пород фундамента на Вездеходной 3 и низкое значение теплового потока. Скважина Вездеходная 1 вскрыла венд-кембрийскую вездеходную толщу, представленную известняками с прослоями доломитов, где были отмечены капельки и плёночки бурого битума. Скважина Мартовская 430 также находится в пределах распространения вездеходной толщи, где вскрыт известняк с большим содержанием органики (битум?) и при испытании совместно нижнеюрских и палеозойских пород получена вода с пленкой нефти. Тепловой поток здесь также не высок (рис. 3).

\section{Выводы}

В результате выполненных исследований получены 38 новых значений плотности теплового потока фундаментального геодинамического параметра для северо-восточной части Томской области. 
Установлена в основном положительная корреляция нефтегазносности, включая нижнеюрский и доюрский комплексы, и напряженности значений теплового поля. Полученные результаты говорят об обоснованности и необходимости второго этапа исследований - расчета генерационного потенциала тогурской свиты, учета вещественного состава нижнеюр-

\section{СПИСОК ЛИТЕРАТУРЫ}

1. Прогноз научно-технологического развития отраслей ТЭК России на период до 2035 года // Минэнерго. 2016. URL: https://minenergo.gov.ru/node/1026 (дата обращения 17.05.2021)

2. Конторович В.А. Тектоника и нефтегазоносность мезозойскокайнозойских отложений юго-восточных районов Западной Сибири. - Новосибирск: Изд-во СО РАН, 2002. - 253 с.

3. Нефтегазоносность коллекторов коры выветривания и палеозоя юго-востока Западной Сибири (прогнозирование трудноизвлекаемых запасов) / Г.А. Лобова, В.И. Исаев, С.Г. Кузьменков, Т.Е. Лунёва, Е.Н. Осипова // Геофизический журнал. - 2018. - Т. 40. - № 4. - С. 73-106.

4. Тепловой поток и термическая история материнской нижнеюрской тогурской свиты и нефтегазоносность палеозоя Колтогорского мезопрогиба (южный сегмент КолтогорскоУренгойского палеорифта) / Г.А. Лобова, Т.Е. Лунева, В.И. Исаев, Ю.В. Коржов, М.Ф. Галиева, Д.С. Крутенко // Геофизический журнал. - 2019. - Т. 41. - № 5. - С. 128-155.

5. Лобова Г.А., Меренкова А.С., Кузьменков С.Г. Тепловой поток, термическая история материнской нижнеюрской тогурской свиты и нефтегазоносность Бакчарской мезовпадины (юго-восток Западной Сибири) // Геофизический журнал. 2020. - T. 42. - № 2. - С. 14-28.

6. Стратегия и основы технологии поисков углеводородов в доюрском основании Западной Сибири / В.И. Исаев, Г.А. Лобова, Ю.В. Коржов, М.Я. Кузина, Л.К. Кудряшова, О.Г. Сунгурова. - Томск: Изд-во ТПУ, 2014. - 112 с.

7. Tissot B.P. Preliminary data on the mechanisms and kinetics of the formation of petroleum in sediments. Computer simulation of a reaction flowsheet // Oil \& Gas Science and Technology - Rev. IFP. - 2003. - V. 58. - № 2. - P. 183-202. DOI https://doi.org/10.2516/ogst:2003013

8. Handhal A.M., Al-Shahwan M.F., Chafeet H.A. Interpretation of hydrocarbon generation, migration and thermal history of Mesopotamian basin Southern Iraq based 1D Petromod software // Iraqi Geological Journal. - 2020. - V. 53. - № 1B. - P. 29-56.

9. Костырева Е.А., Москвин В.И., Ян П.А. Геохимия органического вещества и нефтегенерационный потенциал нижнеюрской тогурской свиты (юго-восток Западной Сибири) // Нефтегазовая геология. Теория и практика. - 2014. - Т. 9. № 1. URL: http://www.ngtp.ru/rub/1/13_2014.pdf (дата обращения 19.05.2021).

10. Катагенез органического вещества в кровле и подошве юрского комплекса Западно-Сибирского мегабассейна / А.Э. Конторович, А.Н. Фомин, В.О. Красавчиков, А.В. Истомин // Геология и геофизика. - 2009. - Т. 50 - № 11. - С. 1875 - 1887.

11. Геохимические критерии нефтегазоносности мезозойских отложений юго-востока Западной Сибири (по результатам бурения скважин Восток-1, 3, 4) / А.Э. Конторович, Е.А. Костырева, В.Н. Меленевский, В.И. Москвин, А.Н. Фомин // Геология нефти и газа. - 2009. - № 1. - С. 4-12.

12. Геологическое строение и сейсмогеологические критерии картирования нефтегазоперспективных объектов нижнеюрских отложений Усть-Тымской мегавпадины / В.А. Конторович, Л.М. Калинина, А.Ю. Калинин, М.В. Соловьев, О.А. Локтионова // Геология нефти и газа. - 2018. - № 6. - С. 81-96.

13. Loktionova O. Geological model and oil-gas-potential of the lower and Middle Jurassic of the Ust-Tym megadepression // Information technologies in solving modern problems of geology and geophysics: VII International Scientific Conference of young scientists and students. Book of Abstracts. - Baku, Azerbaijan, October 15-18, 2018. - P. 40-142.

14. Hantschel T., Kauerauf A.I. Fundamentals of basin and petroleum systems modeling. -Heidelberg, Springer, 2009. -476 p. ских и доюрских комплексов и последующего проведения районирования и ранжирования этой территории по перспективности.

Авторы благодарят рещензентов за внимательную проработку статьи и замечания, способствующие улучшению аргументации выводов.

15. Optical thermal maturity parameters and organic geochemical alteration at low grade diagenesis to anchimetamorphism: a review / C. Hartkopf-Fröder, P. Königshof, R. Littke, J. Schwarzbauer // International Journal of Coal Geology. 2015. - V. 150. - P. 74-119. URL: http://dx.doi.org/10.1016/ j.coal.2015.06.005 (дата обращения 19.05.2021).

16. Тепловой поток и нефтегазоносность (полуостров Ямал, Томская область) / В.И. Исаев, Г.А. Лобова, А.Н. Фомин, В.И. Булатов, С.Г. Кузьменков, М.Ф. Галиева, Д.С. Крутенко // Геоpecypсы. - 2019. - T. 21. - № 3. - C. 125-135. URL: https://geors.ru/archive/journal/74/ (дата обращения 19.05.2021).

17. Petroleum system evolution in the inverted Lower Saxony Basin, northwest Germany: a 3D basin modeling study / B. Bruns, R. di Primio, U. Berner, R. Littke // Geofluids. - 2012. - V. 13. № 2. -26 p. DOI: http://doi.org/10.1111/gfl.12016

18. Reconstruction of the Cenozoic history of hydrocarbon fluids from rifting stage to passive continental margin stage in the Huizhou Sag, the Pearl River Mouth Basin / Ya. Li, Sh. Jiang, Zh. Jiang, H. Liu, B. Li // Geofluids. - 2017. - V. 2017. - 32 p. DOI: https://doi.org/10.1155/2017/4358985

19. Reconstruction of burial history, temperature, source rock maturity and hydrocarbon generation in the northwestern Dutch offshore / R.A. Fattah, J.M. Verweij, N. Witmans, J.H. ten Veen // Netherlands Journal of Geosciences. - 2012. - V. 91. - № 4. P. 535-554. URL: https://doi.org/10.1017/S0016774600000378 (дата обращения 19.05.2021).

20. Heat flow evolution, subsidence and erosion in Upper Silesian Coal Basin, Czech Republic / E. Geršlová, M. Goldbach, M. Geršl, P. Skupien // International Journal of Coal Geology. - 15 January 2016. - V. 154-155. - P. 30-42. URL: https://doi.org/10.1016/j.coal.2015.12.007 (дата обращения 19.05.2021).

21. Обобщение стационарной задачи геотермии Рэлея-Тихонова для горизонтального слоя / В.И. Старостенко, Р.И. Кутас, В.Н. Шуман, О.В. Легостаева // Физика Земли. - 2006. № 12. - C. 84-91.

22. Палеоклиматические факторы реконструкции термической истории баженовской и тогурской свит юго-востока Западной Сибири / В.И. Исаев, А.А. Искоркина, Г.А. Лобова, А.Н. Фомин // Геофизический журнал. - 2016. - Т. 38. - № 4. - С. 3-25.

23. Ермаков В.И., Скоробогатов В.А. Тепловое поле и нефтегазоносность молодых плит СССР. - М.: Недра, 1986. - 222 с.

24. Kutas R.I., Kobolev V.P. The thermal regime of the southern margin East-European craton. IOP Conference Series: Earth and Environmental Science. - 2019. - V. 249. URL: https://doi.org/10.1088/1755-1315/249/1/012034 (дата обращения 19.05.2021)

25. Xiang C., Pang X., Danisik M. Post-Triassic thermal history of the Tazhong Uplift Zone in the Tarim Basin, Northwest China: Evidence from apatite fission-track thermochronology // Geoscience Frontiers. - 2013. - № 4. - P. 743-754. URL: https://doi.org/10.1016/j.gsf.2012.11.010 (дата обращения 19.05.2021).

26. Kim C.-S. Automated reconstruction of a basin thermal history with integrated paleothermometry and genetic algorithm. Soft computing for reservoir characterization and modeling. - 2002. V. 80. - P. 313-329. URL: https://doi.org/10.1007/978-3-79081807-9_13 (дата обращения 19.05.2021).

27. Towards stratigraphic-thermo-mechanical numerical modelling: integrated analysis of asymmetric extensional basins / A. Balázs, L. Maţenco, D. Granjeon, K. Alms, T. François, O. Sztanó // Global and Planetary Change. - 2021. - V. 196. - P. 1-21. URL: https://doi.org/10.1016/j.gloplacha.2020.103386 (дата обращения 19.05.2021) 
28. Theissen S., Rüpke L.H. Feedbacks of sedimentation on crustal heat flow: new insights from the Voring Basin, Norwegian Sea // Basin Research. - 2010. - V. 22. - P. 976-990. URL: https://doi.org/10.1111/j.1365-2117.2009.00437 (дата обращения 19.05.2021)
29. Исаев Г.Д. Геология и тектоника палеозоя Западной Сибири // Литосфера. - 2010. - № 4. - С. 52-68.

Поступила 09.06.2021 г.

\section{Информация об авторах}

Лобова Г.А., доктор геолого-минералогических наук, профессор отделения геологии Инженерной школы природных ресурсов Национального исследовательского Томского политехнического университета.

Меренкова A.C., аспирант отделения геологии Инженерной школы природных ресурсов Национального исследовательского Томского политехнического университета.

Исаев В.И., доктор геолого-минералогических наук, профессор отделения геологии Инженерной школы природных ресурсов Национального исследовательского Томского политехнического университета.

Кузьменков С.Г., доктор геолого-минералогических наук, профессор Института нефти и газа Югорского государственного университета. 
UDC 553/98

\title{
HEAT FLOW AND OIL AND GAS PRESENCE OF THE TOMSK REGION NORTH-EASTERN PART
}

\author{
Galina A. Lobova1, \\ lobovaga@tpu.ru
}

Anna S. Merenkova ${ }^{1}$, a.merenckowa@yandex.ru

Valery I. Isaev'1,
isaevvi@tpu.ru

Stanislav G. Kuzmenkov², ksg.1948@yandex.ru

1 National Research Tomsk Polytechnic University, 30, Lenin avenue, Tomsk, 634050, Russia.

2 Yugra State University, 16, Chehov avenue, Khanty-Mansiysk, 628012, Russia.

The relevance of the study of the north-eastern part of the Tomsk region is determined by the need to search for new sources of replenishment of the resource base, defined by the strategy for oil industry development in the Russian Federation until 2035.

The main aim of the research is to determine the heat flow density from the bottom of the sedimentary section by solving the inverse problem of geothermics. It includes the anomalous zones correlation of the obtained parameter with the established oil and gas content and the prospects determination of the north-eastern lands of the Tomsk region for the Lower Jurassic and pre-Jurassic deposits.

The objects of the research are the north-eastern lands of the Tomsk region belonging to the territory of widespread Hettangian-Lower Toarcian. There are potential oil-source Togur deposits having certain similarity in geological structure with oil-producing regions. The temperatures measured in 38 exploration and parametric representative wells were used to determine the heat flow density.

Research methods include the collection and analysis of geological and geophysical data on deep wells drilled in the research area, $1 D$ paleotemperature modeling combined with paleotectonic reconstructions using a domestic software product.

The result. The authors have built a map with a cross-section of isolines of $2,5 \mathrm{~mW} / \mathrm{m}^{2}$ based on the calculated values of the heat flow in the wells by the interpolation method. The analysis of the performed constructions shows that the thermal field on the top of the basement in the north-eastern part of the Tomsk region is heterogeneous. Its values vary from 33 to $69 \mathrm{~mW} / \mathrm{m}^{2}$. The zone of increased values of the heat flow density extends from north-west to south-east, crossing tectonic structures. A decrease in the intensity of the geothermal field is observed in the north-eastern and eastern sections. The increased values of the heat flow, in general, correlate with the established oil and gas content in the study area. Within the southern part of the Karamka Mesotrough, high prospects are expected in the Lower Jurassic and Pre-Jurassic complexes. High prospects for oil and gas content can be noted in the area of the Yuzhno-Pyzhinskaya 1 parametric well and lands located in the East Paiduga Megadepression, where the thickness of the Lower Jurassic deposits and the magnitude of the heat flow are increased.

Conclusions. The authors obtained new data on the heat flow density in the Tomsk region north-eastern part. The study area is promising for further prospecting and exploration work with the aim of discovering deposits in the Lower Jurassic and pre-Jurassic objects.

\section{Key words:}

Oil source Togur deposits, paleotemperature and paleotectonic modeling, heat flow density, oil and gas content, Lower Jurassic and preJurassic deposits, northeast of the Tomsk region.

The authors are thankful to the reviewers for thoughtful work with the paper and comments, contributing to improvement of reasoning conclusions.

\section{REFERENCES}

1. Prognoz nauchno-tekhnologicheskogo razvitiya otrasley TEK Rossii na period do 2035 goda [Forecast of scientific and technological development of the sectors of the Fuel and Energy Complex of Russia for the period up to 2035]. 2016. Available at: https://minenergo.gov.ru/node/8914 (accessed 17 May 2021).

2. Kontorovich V.A. Tektonika $i$ neftegazonosnost mezozoyskokaynozoyskih otlozheniy yugo-vostochnykh rayonov Zapadnoy Sibiri [Tectonics and oil and gas potential of the MesozoicCenozoic sediments of the Western Siberia southeastern regions]. Novosibirsk, SB RAS Publ., 2002. 253 p.

3. Lobova G.A., Isaev V.I., Kuzmenkov S.G., Luneva T.E., Osipova E.N Oil and gas reservoirs of weathering crusts and Paleozoic basement in the southeast of Western Siberia (forecasting of hard-torecover reserves). Geofizicheskiy zhurnal, 2018, vol. 40, no. 4, pp. 73-106. In Rus.
4. Lobova G.A., Luneva T.E., Isaev V.I., Korzhov Yu.V., Galieva M.F., Krutenko D.S. The heat flow, thermal history of the source Lower Jurassic Togurskaya suite and oil-and-gas potential of the Paleozoic of the Koltogor mezodepression (southern segment of the Koltogor-Urengoy paleorift). Geofizicheskii zhurnal, 2019, vol. 41, no. 5, pp. 128-155. In Rus.

5. Lobova G.A., Merenkova A.S., Kuzmenkov S.G. Heat flow, thermal history of the source Lower Jurassic Togur suite and hydrocarbon presence in the Bakchar mezodepression (South-East of West Siberia). Geofizicheskii zhurnal, 2020, vol. 42, no. 2, pp. 128-155. In Rus.

6. Isaev V.I., Lobova G.A., Korzhov Yu.V., Kuzina M.Ya., Kudryashova L.K., Sungurova O.G. Strategiya $i$ osnovy tekhnologii poiskov uglevodorodov $v$ doyurskom osnovanii Zapadnoy Sibiri [Strategy and basis of technologies for hydrocarbon exploration in the pre-Jurassic basement of Western Siberia]. Tomsk, TPU Publ. house, 2014. 112 p. 
7. Tissot B.P. Preliminary data on the mechanisms and kinetics of the formation of petroleum in sediments. Computer simulation of a reaction flowsheet. Oil \& Gas Science and Technology. Rev. IFP, 2003, vol. 58, no. 2, pp. 183-202. DOI: https://doi.org/10.2516/ogst:2003013

8. Handhal A.M., Al-Shahwan M.F., Chafeet H.A. Interpretation of hydrocarbon generation, migration and thermal history of Mesopotamian basin Southern Iraq based 1D Petromod software. Iraqi Geological Journal, 2020, vol. 53, no. 1B, pp. 29-56.

9. Kostyreva E.A., Moskvin B.I., Yan P.A. Geochemistry of organic matter and oil generation potential of the Lower Jurassic Togur formation (south-heast of Western Siberia). Neftegazovya geologia. Teoria i praktika, 2014, vol. 9, no. 1. In Rus. Available at: http://www.ngtp.ru/rub/1/13_2014.pdf (accessed 19 May 2021).

10. Kontorovich A.E., Fomin A.N., Krasavchikov V.O., Istomin A.V. Katagenez organicheskogo veshchestva v krovle i podoshve yurskogo kompleksa Zapadno-Sibirskogo megabasseyna [Catagenesis of organic matter in the top and bottom of the West Siberian megabasin Jurassic complex]. Geologiya i geofizika, 2009, vol. 50, no. 11 , pp. $1875-1887$.

11. Kontorovich A.E., Kostyreva E.A., Moskvin V.I., Fomin A.N. Geokhimicheskie kriterii neftegazonosnosti mezozoyskikh otlozheniy yugo-vostoka Zapadnoy Sibiri (po rezultatam bureniya skvazhin Vostok-1, 3, 4) [Geochemical criteria for the oil and gas content of Mesozoic sediments in the Western Siberia southeast (based on the results of drilling Vostok-1, 3, 4 wells)]. Geologiya negti i gaza, 2009, no. 1, pp. 4-12.

12. Kontorovich V.A., Kalinina L.M., Kalinin A.Yu., Solovev M.V., Loktionova O.A. Geologicheskoe stroenie i seysmogeologicheskie kriterii kartirovaniya neftegazoperspektivnykh obektov nizhneyurskikh otlozheniy Ust-Tymskoy megavpadiny [Geological structure and seismogeological criteria for oil and gas promising objects mapping in the Lower Jurassic deposits of the Ust-Tym megadepression]. Geologiya nefti i gaza, 2018, no. 6, pp. 81-96.

13. Loktionova O. Geological model and oil-gas-potential of the lower and Middle Jurassic of the Ust-Tym megadepression. Information technologies in solving modern problems of geology and geophysics: VII International Scientific Conference of young scientists and students. Book of Abstracts. Baku, Azerbaijan, October 15-18, 2018. pp. 40-142.

14. Hantschel T., Kauerauf A.I. Fundamentals of basin and petroleum systems modeling. Heidelberg, Springer, 2009. $476 \mathrm{p}$.

15. Hartkopf-Fröder C., Königshof P., Littke R., Schwarzbauer J. Optical thermal maturity parameters and organic geochemical alteration at low grade diagenesis to anchimetamorphism: a review. International Journal of Coal Geology, 2015, vol. 150, pp. 74-119. Available at: http://dx.doi.org/10.1016/j.coal.2015.06.005 (accessed 19 May 2021).

16. Isaev V.I., Lobova G.A., Fomin A.N., Bulatov V.I., Kuzmenkov S.G., Galieva M.F., Krutenko D.S. Heat flow and oil and gas potential (the Yamal peninsula, Tomsk Region). Georesources, 2019, vol. 21, no. 4, pp. 125-135. In Rus.

17. Bruns B., di Primio R., Berner U. Littke R.Petroleum system evolution in the inverted Lower Saxony Basin, northwest Germany: a 3D basin modeling study. Geofluids, 2012, vol. 13, no. 2, 26 p. DOI: http://doi.org/10.1111/gfl.12016

\section{Information about the authors}

Galina A. Lobova, Dr. Sc., professor, National Research Tomsk Polytechnic University.

Anna S. Merenkova, postgraduate student, National Research Tomsk Polytechnic University.

Valery I. Isaev, Dr. Sc., professor, National Research Tomsk Polytechnic University.

Stanislav G. Kuzmenkov, Dr. Sc., professor, Yugra State University.
18. Li Ya., Jiang Sh., Jiang Zh., Liu H., Li B. Reconstruction of the Cenozoic history of hydrocarbon fluids from rifting stage to passive continental margin stage in the Huizhou Sag, the Pearl River Mouth Basin. Geofluids, 2017, vol. 2017, 32 p. DOI: https://doi.org/10.1155/2017/4358985

19. Fattah R.A., Verweij J.M., Witmans N., ten Veen J.H. Reconstruction of burial history, temperature, source rock maturity and hydrocarbon generation in the northwestern Dutch offshore. Netherlands Journal of Geosciences, 2012, vol. 91, no. 4, pp. 535-554. DOI: https://doi.org/10.1017/S0016774600000378

20. Geršlová E., Goldbach M., Geršl M., Skupien P. Heat flow evolution, subsidence and erosion in Upper Silesian Coal Basin, Czech Republic. International Journal of Coal Geology, 2016, vol. 154-155, pp. 30-42. DOI: https://doi.org/10.1016/j.coal.2015.12.007

21. Starostenko V.I., Shuman V.N., Legostaeva O.V. Obobshchenie statsionarnoy zadachi geotermii Releya-Tikhonova dlya gorizontalnogo sloya [Generalization of the stationary Rayleigh-Tikhonov geothermal problem for a horizontal layer]. Fizika Zemli, 2006, no. 12, pp. 84-91.

22. Isaev V.I., Iskorkina A.A., Lobova G.A., Fomin A.N. Paleoclimatic factors of reconstruction of thermal history of parent petroleum bazhenov and togur suites of southeast of West Siberia. Geofizicheskii zhurnal, 2016, vol. 38, no. 4, pp. 3-25. In Rus.

23. Ermakov V.I., Skorobogatov V.A. Teplovoe pole i neftegazonosnost molodykh plit SSSR [Thermal field and oil and gas content of young plates of the USSR]. Moscow, Nedra Publ., 1986. 222 p.

24. Kutas R.I., Kobolev V.P. The thermal regime of the southern margin East-European craton. IOP Conference Series: Earth and Environmental Science, 2019, vol. 249. URL: https://doi.org/10.1088/ 1755-1315/249/1/012034 (accessed 19 May 2021)

25. Xiang C., Pang X., Danisik M. Post-Triassic thermal history of the Tazhong Uplift Zone in the Tarim Basin, Northwest China: evidence from apatite fission-track thermochronology. Geoscience Frontiers, 2013, no. 4, pp. 743-754. DOI: https://doi.org/10.1016/.gsf.2012.11.010

26. Kim C.-S. Automated reconstruction of a basin thermal history with integrated paleothermometry and genetic algorithm. Soft computing for reservoir characterization and modeling. SpringerVerlag Berlin Heidelberg, 2002, vol. 80, pp. 313-329. DOI: https://doi.org/10.1007/978-3-7908-1807-9_13

27. Balázs A., Maţenco L., Granjeon D., Alms K., François T., Sztanó $\mathrm{O}$. Towards stratigraphic-thermo-mechanical numerical modelling: Integrated analysis of asymmetric extensional basins. Global and Planetary Change, 2021, vol. 196, pp. 1-21. DOI: https://doi.org/10.1016/j.gloplacha.2020.103386

28. Theissen S., Rüpke L.H Feedbacks of sedimentation on crustal heat flow: new insights from the Voring Basin, Norwegian Sea. Basin Research, 2010, vol. 22, pp. 976-990. DOI: https://doi.org/10.1111/j.1365-2117.2009.00437

29. Isaev G.D. Geologiya i tektonika paleozoya Zapadnoy Sibiri [Geology and tectonics of the Western-Siberian plate Paleozoic basement]. Litosfera, 2010, no. 4, pp. 52-68.

Received: 9 June 2021. 